\title{
STRES DAN STRATEGI KOPING ANAK JALANAN DI KOTA DEPOK
}

\author{
Berliana $^{1, *}$, Ice Yulia Wardani ${ }^{2}$ \\ ${ }^{1}$ Program Studi Sarjana Ilmu Keperawatan, Fakultas Ilmu Keperawatan, Universitas Indonesia, \\ Kampus FIK UI, J1. Prof. Dr. Bahder Djohan, Depok, Jawa Barat -16424, Indonesia \\ ${ }^{2}$ Dosen Keilmuan Keperawatan Jiwa Fakultas Imu Keperawatan, Universitas Indonesia, \\ Kampus FIK UI, J1. Prof. Dr. Bahder Djohan, Depok, Jawa Barat -16424, Indonesia \\ *)Email: berlian25berlin@gmail.com
}

Diterima: April 2017, diterbitkan: Agustus 2017

\begin{abstract}
ABSTRAK
Arus urbanisasi dan kemiskinan membuat fenomena anak jalanan meningkat. Banyak stresor yang membuat anak mengalami stres sehingga membutuhkan suatu strategi untuk mengatasinya. Tujuan penelitian: Penelitian ini bertujuan untuk mengetahui karakteristik, tingkatan stres, dan strategi koping anak jalanan di SMP Master Kota Depok. Metode: Penelitian ini merupakan penelitian deskriptif sederhana. Pengambilan sampel mengunakan teknik total sampling. Jumlah sampel sebanyak 50 anak. Pengumpulan data dilakukan di SMP Master dengan kuesioner yang diadaptasi dari Perceived Stress Scale dan Ways of Coping yang telah diuji validitas dan reliabilitasnya pada April 2017. Analisis data penelitian menggunakan analisis univariat yang menggambarkan karakteristik, tingkatan stres, dan strategi koping anak. Hasil penelitian: Karakteristik responden adalah remaja dengan rata-rata usia 14 tahun, pekerjaannya berdagang (32\%), memiliki pengalaman dikucilkan (66\%), mempunyai pengalaman kekerasan fisik (40\%), pengalaman berpindahpindah tempat tinggal (54\%), dan tidak menggunakan narkoba (90\%). Mayoritas anak jalanan di SMP Master Kota Depok (88\%) mengalami stres sedang. Adapun jenis strategi koping yang sering digunakan ialah emotional focused coping (60\%). Saran: Hasil penelitian ini memberikan rekomendasi perawat agar dapat memfasilitasi kegiatan yang memberikan informasi mengenai cara menangani stres dengan strategi koping melalui kegiatan penyuluhan kesehatan jiwa dan pendampingan pemenuhan tugas perkembangan remaja.
\end{abstract}

Kata Kunci: tingkat stres, strategi koping, anak jalanan

\section{STRESS AND COPING STRATEGY IN STREET CHILDREN AT DEPOK CITY}

\section{Abstract}

Urbanization and poverty increase the phenomenon of street children. Children experience stress due to a number of stressors that a strategy is required to deal with them. Objective: This research aims to identify characteristics, levels of stress, and coping strategy in street children at Junior High School of Master, Depok City. Methods: This research is a simple descriptive research with a sample size of 50 children whom were taken using total sampling. Data were collected at Junior High School of Master by using questionnaires adapted from Perceived Stress Scale and Ways of Coping of which validity and reliability had been tested in April 2017. Data were analyzed using univariate analysis which described characteristics, levels of stress, and coping strategy in children. Results: The characteristics of respondents were adolescents with an average age of 14 years, working in trading (32\%), having experience of being isolated (66\%), having experience of physical violence (40\%), having experience of moving from place to place (54\%), and not using drugs (90\%). The majority of street children Junior High School of Master in Depok City (88\%) experience moderate stress. The most frequently used coping strategy was Emotional Focused Coping (60\%). Suggestion: The results of this research recommend that nurses facilitate activities that provide information about how to deal with stress with coping strategies through mental health counseling activities and mentoring to fulfill adolescent development tasks.

Keywords: stres level, coping strategies, street children 


\section{PENDAHULUAN}

Setiap anak memiliki hak untuk mendapatkan kesejahteraan dan perlindungan agar dapat tumbuh dan berkembang. Saat ini, arus urbanisasi dan kemiskinan yang semakin meningkat membuat fenomena anak jalanan juga mengalami peningkatan (UNICEF, 2012). Sebagian besar anak jalanan berusia 5-18 tahun yang seharusnya mendapatkan asuhan yang layak dari orangtuanya (Badan Pusat Statistik Provinsi Jawa Barat, 2015). Akan tetapi, anak jalanan terbiasa menghabiskan sebagian waktunya untuk mencari nafkah tanpa perlindungan yang memadai. Hal ini menyebabkan anak menghadapi beragam stresor yang membuatnya mengalami stres dan membutuhkan suatu strategi untuk menghadapinya.

UNICEF (2012) mendefinisikan anak jalanan sebagai anak laki-laki atau perempuan yang belum mencapai usia dewasa yang menghabiskan seluruh atau sebagian waktu mereka di jalan untuk sekadar berdiam atau menjadikan jalan sebagai sumber mata pencarian. Berdasarkan data dari Kementerian Sosial Republik Indonesia yang ditulis oleh Hamid (2010), pada tahun 1997 jumlah anak jalanan di Indonesia sekitar 36.000 anak, sedangkan pada tahun 2010 jumlahnya menjadi 232.894 anak. Kota Depok menduduki peringkat ketiga dengan jumlah anak jalanan terbanyak di Provinsi Jawa Barat (Badan Pusat Statistik Jawa Barat, 2015).

Lazarus \& Folkman (1984) mendefinisikan stres adalah suatu hal yang mengancam sebagai akibat dari interaksi antara individu dan lingkungan yang membuat individu menilai hal tersebut sebagai suatu ketidaksesuaian antara kemampuan individu baik secara fisik, psikologis, dan sistem sosial dengan tuntutan atau ancaman tersebut. Sementara itu, situasi atau kondisi yang menyebabkan individu bereaksi atau merasakan stres disebut stresor. Stresor yang mungkin ditemukan oleh anak jalanan adalah masalah sosial, masalah fisik, dan masalah psikologi (WHO, 2010). Stres dapat ditandai dengan adanya gejala kognitif, gejala emosional, gejala fisik, dan gejala perilaku (Segal et al., 2016). Sementara itu, stres dikategorikan menjadi stres ringan, sedang, dan berat (Potter \& Perry, 2009).

Setiap individu yang menghadapi permasalahan dan mengalami stres pasti akan melakukan sesuatu untuk menghilangkan rasa stresnya. Menurut Lazarus \& Folkman (1984), koping merupakan upaya kognitif dan perilaku yang dilakukan sebagai usaha untuk menguasai, menoleransi, atau mengurangi tuntutan yang berasal dari internal maupun eksternal. Strategi koping ini dikategorikan ke dalam problem focused coping dan emotional focused coping.

Kurangnya kesiapan anak jalanan menghadapi stresor yang ditemukan di jalanan dapat menyebabkan stres pada anak jalanan di Kota Depok, khususnya anak jalanan yang ada di SMP Master. Mengingat manusia merupakan makhluk yang unik, respons terhadap stres yang dilakukan oleh setiap anak juga pasti berbeda. Hal ini akan menjadi masalah yang cukup penting dan menarik untuk diteliti. Berdasarkan uraian tersebut, peneliti tertarik untuk meneliti bagaimana gambaran tingkat stres dan strategi koping pada anak jalanan di SMP Master Kota Depok.

\section{METODE}

Penelitian ini menggunakan desain penelitian deskriptif kuantitatif sederhana terhadap suatu komunitas atau kelompok dan pengambilan sampelnya menggunakan teknik total sampling. Jumlah responden dalam penelitian ini ialah 50 anak yang berasal dari seluruh kelas di SMP Master Kota Depok 
dengan kriteria inklusi: anak yang mencari penghasilan di jalanan, anak yang masih memiliki tempat tinggal, tinggal bersama keluarga, mampu membaca dan menulis, serta bersedia untuk menjadi responden dalam penelitian ini.

Instrumen yang digunakan pada penelitian ini ialah kuesioner Perceived Stress Scale yang dikembangkan oleh Cohen et al. (1983) dan Ways of Coping Questionnaire yang dikembangkan oleh Lazarus \& Folkman (1984) dengan skala Likert. Responden diminta untuk memberikan tanda $(\sqrt{ })$ pada kolom yang telah ditentukan. Instrumen tingkatan stres memiliki 10 pernyataan dan instrumen strategi koping memiliki 23 pernyataan. Hasil perhitungan menunjukkan tingkatan stres yang dialami dan dikategorikan menjadi stres ringan dengan total nilai $0-13$, stres sedang dengan total nilai $14-26$, serta stres berat dengan total nilai 27-40.

Strategi koping dikategorikan menjadi problem focused coping dan emotional focused coping dengan cara menghitung total raw scores dan relative scores. Problem focused coping terbagi ke dalam tiga subvariat, yaitu confrontive coping, seeking social support, dan planful problem solving. Sementara itu, emotinal focused coping terbagi ke dalam lima subvariat, yaitu positive reappraisal, distancing, self controlling, accepting responsibility, dan escape avoidance. Jenis analisis yang digunakan ialah analisis univariat. Hasil dari analisis univariat ini berupa distribusi frekuensi karakteristik anak jalanan di SMP Master Kota Depok, tingkatan stres, dan strategi koping yang digunakannya.
Sebelum melakukan pengambilan data, peneliti melakukan uji validitas dan reliabilitas di Yayasan Bina Nusantara Pasar Minggu atas pertimbangan karakteristik yang hampir sama dengan anak jalanan yang bersekolah di SMP Master Kota Depok. Uji validitas dan reliabilitas dilakukan terhadap 30 anak jalanan. Pada hasil uji validitas kuesioner Perceived Stress Scale didapatkan nilai r berkisar antara 0,444-0,619 ( $r$ tabel=0,361), pada uji reliabilitas didapatkan nilai $r$ alfa $=0,860$. Pada uji validitas kuesioner Ways of Coping didapatkan nilai $r$ antara 0,393-0,685 dan pada hasil uji reliabilitas didapatkan nilai $r$ alfa $=0,847$. Berdasarkan hal tersebut dapat disimpulkan bahwa kedua kuesioner valid dan reliabel.

Tahap selanjutnya peneliti mengajukan izin penelitian di SMP Master Kota Depok. Setelah mendapatkan izin penelitian, peneliti mulai melakukan pengambilan data dengan memperhatikan etika penelitian yang meliputi menghormati harkat dan martabat manusia, privasi dan kerahasiaan responden, keadilan dan inklusivitas, serta manfaat dan kerugian yang ditimbulkan.

\section{HASIL}

Jumlah responden pada penelitian ini adalah 50 anak yang termasuk ke dalam kriteria inklusi yang telah ditentukan oleh penulis. Distribusi karakteristik, tingkat stres, dan strategi koping pada anak jalanan di SMP Master Kota Depok dapat dilihat pada uraian dan tabel-tabel berikut.

Responden penelitian ini ialah anak jalanan dengan rata-rata usia 14,34 tahun. Usia termuda anak jalanan di SMP Master 12 tahun dan usia tertua 18 tahun. 
Tabel 1. Distribusi frekuensi pekerjaan, pengalaman, dan pola asuh anak jalanan di SMP Master Kota Depok

\begin{tabular}{|c|c|c|c|}
\hline \multicolumn{4}{|c|}{$(n=50)$} \\
\hline No. & Karakteristik & $\mathbf{n}$ & $\%$ \\
\hline \multirow[t]{6}{*}{1.} & Pekerjaan & & \\
\hline & Berjualan & 16 & $32 \%$ \\
\hline & Mengamen & 13 & $26 \%$ \\
\hline & Ojek & 4 & $8 \%$ \\
\hline & Pemulung & 9 & $18 \%$ \\
\hline & Lainnya & 8 & $16 \%$ \\
\hline \multirow[t]{3}{*}{2.} & $\begin{array}{l}\text { Pengalaman Dikucilkan/ } \\
\text { Diasingkan }\end{array}$ & & \\
\hline & $\mathrm{Ya}$ & 33 & $66 \%$ \\
\hline & Tidak & 17 & $34 \%$ \\
\hline \multirow[t]{3}{*}{3.} & $\begin{array}{l}\text { Pengalaman Kekerasan } \\
\text { Fisik/Seksual }\end{array}$ & & \\
\hline & $\mathrm{Ya}$ & 20 & $40 \%$ \\
\hline & Tidak & 30 & $60 \%$ \\
\hline \multirow[t]{3}{*}{4.} & $\begin{array}{l}\text { Pengalaman Berpindah } \\
\text { Tempat Tinggal }\end{array}$ & & \\
\hline & Ya & 27 & $54 \%$ \\
\hline & Tidak & 23 & $46 \%$ \\
\hline \multirow[t]{3}{*}{5.} & $\begin{array}{l}\text { Pengalaman } \\
\text { Penggunaan NAPZA }\end{array}$ & & \\
\hline & Ya & 5 & $10 \%$ \\
\hline & Tidak & 45 & $90 \%$ \\
\hline \multirow[t]{4}{*}{6.} & Pola Asuh & & \\
\hline & Otoritatif & 21 & $42 \%$ \\
\hline & Otoriter & 24 & $48 \%$ \\
\hline & Permissif & 5 & $10 \%$ \\
\hline
\end{tabular}

Tabel 1 menjelaskan karakteristik mengaku memiliki pengalaman berpindahanak jalanan di SMP Master Kota Depok. pindah tempat tinggal, sebagian besar Sebagian besar (32\%) anak bekerja dengan (90\%) anak jalanan mengaku tidak pernah berdagang dan $66 \%$ mengaku memiliki menggunakan NAPZA. Jenis pola asuh yang pengalaman dikucilkan atau diasingkan sering diterima oleh sebagian besar anak sejak lahir sampai saat ini oleh lingkungan. jalanan di SMP Master Kota Depok (48\%) Data terkait pengalaman kekerasan fisik atau adalah pola asuh otoriter. seksual dialami oleh $40 \%$ anak dan $54 \%$ anak

Tabel 2. Distribusi frekuensi tingkat stres anak jalanan di SMP Master Kota Depok $(n=50)$

\begin{tabular}{lrr}
\hline \multicolumn{1}{c}{ Tingkat Stres } & Jumlah (n) & \multicolumn{1}{c}{$\%$} \\
\hline Stres ringan & 3 & $6 \%$ \\
Stres sedang & 44 & $88 \%$ \\
Stres berat & 3 & $6 \%$ \\
Total & $\mathbf{5 0}$ & $\mathbf{1 0 0 \%}$ \\
\hline
\end{tabular}

Tabel 2 menjelaskan tingkatan stres pada sebanyak 44 anak (88\%) di SMP Master Kota anak jalanan di SMP Master Kota Depok. Depok mengalami stres sedang, 3 anak (6\%) Berdasarkan hasil analisis, didapati bahwa 
mengalami stres ringan, dan 3 anak (6\%) mengalami stres berat.

Tabel 3. Strategi koping anak jalanan di SMP Master Kota Depok $(n=50)$

\begin{tabular}{llr}
\hline No. & \multicolumn{1}{c}{ Strategi Koping } & $\%$ \\
\hline 1. & Problem focused coping & $40 \%$ \\
2. & Emotional focused coping & $60 \%$ \\
& Total & $\mathbf{1 0 0 \%}$ \\
\hline
\end{tabular}

Tabel 3 merupakan gambaran distribusi lainnya memilih problem focused coping dalam strategi koping yang digunakan oleh anakjalanan menghadapi masalah. Problem focus coping di SMP Master Kota Depok. Berdasarkan tabel merupakan kemampuan penyelesaian masalah tersebut, strategi koping yang paling sering dengan melibatkan kemampuan intrapersonal digunakan oleh anak ialah emotional focused individu. coping (60\%). Kemudian, sebanyak $40 \%$ anak

Tabel 4. Distribusi frekuensi subvariabel problem focused coping pada anak jalanan di SMP

Master Kota Depok $(n=50)$

\begin{tabular}{llc}
\hline No & \multicolumn{1}{c}{ Subvariabel } & $\%$ \\
\hline 1. & Confrontive coping & $50 \%$ \\
2. & Seeking social support & $40 \%$ \\
3. & Planful problem solving & $10 \%$ \\
& Total & $\mathbf{1 0 0 \%}$ \\
\hline
\end{tabular}

Tabel 4 menggambarkan distribusi (26,7\%) dan self controlling (26,7\%), disusul frekuensi strategi koping berdasarkan subvariabel oleh accepting responsibility (23,3\%), positive emotional focused coping, sub-sub variabel reappraisal (13,3\%), dan escape avoidance yang paling sering digunakan adalah distancing (10\%).

Tabel 5. Distribusi frekuensi subvariabel emotional focused coping pada anak jalanan di SMP Master Kota Depok $(n=50)$

\begin{tabular}{clr}
\hline No & \multicolumn{1}{c}{ Subvariabel } & \multicolumn{1}{c}{$\%$} \\
\hline 1. & Positive reappraisal & $13,3 \%$ \\
2. & Distancing & $26,7 \%$ \\
3. & Self controlling & $26,7 \%$ \\
4. & Accepting responsibility & $23,3 \%$ \\
5. & Escape avoidance & $10 \%$ \\
& Total & $\mathbf{1 0 0 \%}$ \\
\hline
\end{tabular}

Tabel 5 menggambarkan distribusi frekuensi strategi koping berdasarkan subvariabel problem focused coping, sub-subvariabel yang paling sering digunakan adalah confrontive coping (50\%), disusul oleh seeking social support (40\%), dan planful problem solving (10\%).

\section{PEMBAHASAN}

Pada penelitian ini didapatkan bahwa sebagian besar anak jalanan mencari uang dengan cara berjualan. Menurut WHO (2010), salah satu alasan atau faktor penyebab anak turun ke jalanan ialah untuk mendapatkan penghasilan atau uang. Berdasarkan hasil penelitian yang didapatkan oleh Purwoko (2013), faktor ekonomi keluarga menjadi alasan utama anak-anak untuk turun ke jalanan. Pendapatan orangtua yang tidak mencukupi untuk memenuhi kebutuhan 
sehari-hari menyebabkan anak-anak turut menanggung beban ekonomi keluarganya.

Hasil penelitian ini juga menunjukkan bahwa (66\%) anak jalanan di SMP Master Kota Depok pernah mengalami tindakan pengucilan dan pengasingan. Hal ini tentunya berdampak terhadap keadaan psikologis anak-anak. Menurut WHO (2010), hal ini termasuk ke dalam masalah sosial yang sering ditemui oleh anak jalanan. Anak jalanan cenderung dikucilkan dari masyarakat umum dan dikecualikan untuk ikut kegiatan dengan anak-anak lain. Keadaan tersebut sejalan dengan hasil penelitian yang diperoleh Persada (2012). Anak jalanan sering kali mendapatkan kekerasan psikologis berupa tindakan pencemoohan, seperti kata-kata kasar dan menyindir yang berasal dari supir angkutan umum dan penumpangnya. Hal tersebut merupakan sumber stres bagi anakanak. Mereka akan merasa tidak dihargai dan diharapkan untuk berada di tengah-tengah masyarakat.

Pada penelitian ini didapatkan sebanyak $40 \%$ anak pernah mengalami tindak kekerasan. Hal tersebut berkaitan dengan hasil yang diperoleh dalam karakteristik pola asuh yang hasilnya menunjukkan sebanyak $48 \%$ anak menerima pola asuh otoriter. Beberapa anak mengaku pernah dipukul, ditampar, dan dicubit oleh orangtuanya ketika mereka melakukan kesalahan di rumah. Dalam hal ini, keluarga bukan menjadi pelindung, melainkan menjadi sumber kekerasan bagi anak-anak jalanan.

Keluarga merupakan unit terkecil dalam masyarakat yang terdiri atas anggotaanggota keluarga dan memiliki perannya masing-masing. Pada keaadaan tertentu, ketidakmampuan salah satu anggota keluarga dalam menjalankan peran akan menyebabkan perubahan pada keluarga tersebut (Lestari, 2012). Hal inilah yang terjadi pada anak jalanan di SMP Master Kota
Depok. Ketidakmampuan orangtua dalam memenuhi kebutuhan hidup mereka membuat orangtua meminta anak untuk membantunya mencari uang di jalanan. Orangtua menuntut anak untuk mengerti kondisi ekonomi yang dialami oleh keluarga. Hal tersebut berkaitan dengan pola asuh otoriter yang diterima oleh sebagian besar anak jalanan di SMP Master Kota Depok. Sejalan dengan hasil penelitian yang diperoleh Noprianto (2015), hasil penelitiannya menunjukkan bahwa pola asuh pada anak jalanan di Makassar ialah jenis pola asuh otoriter.

Pola asuh otoriter ditandai dengan kondisi orangtua yang selalu menuntut, mengendalikan, serta menekankan keinginan mereka terhadap anak. Pada masyarakat golongan menengah ke bawah, orangtua cenderung memiliki sikap yang lebih keras jika dibandingkan dengan orangtua dari golongan menengah ke atas. Dengan demikian, orangtua tidak segan memukul atau melakukan tindak kekerasan apabila terdapat sesuatu hal di luar kehendaknya (Noprianto, 2015).

Anak dituntut untuk membantu menopang kebutuhan ekonomi keluarga dengan cara turun ke jalanan. Apabila anak tidak dapat memenuhi tuntutan tersebut, orangtua cenderung kecewa, marah, ataupun kesal terhadap anak. Oleh karena itu, anak lebih senang berada di jalanan karena merasa bebas dari tuntutan orangtuanya (WHO, 2010).

Selain itu, pada penelitian ini juga ditemukan sebanyak 5\% anak jalanan di SMP Master Kota Depok pernah menggunakan NAPZA (narkotika, psikotropika, dan zat adiktif lainnya). Hasil penelitian ini berbeda dari hasil penelitian yang didapatkan oleh Nugroho (2012) yang 100\% respondennya mengaku pernah menggunakan NAPZA. Hal ini disebabkan anak jalanan di SMP Master Kota Depok sudah melalui tahapan 
pendidikan dan pengawasan dari pihak sekolah.

Peraturan SMP Master Kota Depok melarang siswa menggunakan NAPZA. Akan tetapi, ada 5\% anak yang pernah menggunakan NAPZA. Hal ini dapat berpotensi membawa dampak buruk bagi anak-anak lain karena anak jalanan sedang berada pada tahap remaja. Pada masa itu anak sedang mencari identitas dirinya. Lingkungan menjadi faktor utama pada anak remaja dalam mendapatkan identitas dirinya.

Potter \& Perry (2009) menjelaskan bahwa stres dikategorikan ke dalam tiga tingkatan, yaitu stres ringan, stres sedang, dan stres berat. Berdasarkan hasil analisis yang telah dilakukan, penulis menemukan bahwa sebagian besar anak jalanan di SMP Master Kota Depok mengalami stres sedang.

Penelitian serupa mengenai tingkatan stres pada anak jalanan juga telah dilakukan oleh Titaheluw, Kanine, \& Kallo (2014) di Manado. Hasil yang diperoleh sedikit berbeda, yakni pada penelitian sebelumnya dari total 20 responden didapatkan 9 di antaranya mengalami stres adaptasi berat, 4 responden mengalami stres adaptasi sedang, 7 responden mengalami stres adaptasi ringan.

Adanya perbedaan hasil penelitian ini kemungkinan dapat disebabkan oleh perbedaan karakteristik anak jalanan yang dijadikan responden. Penelitian ini dilakukan pada anak-anak jalanan yang masih memiliki orangtua dan masih mendapatkan asuhan orangtua, serta masih menjalankan pendidikan di SMP Master. Sementara itu, pada penelitian sebelumnya responden yang ditemukan di Pasar Bersehati Manado. Dengan demikian, stresor yang ditemukan oleh masing-masing responden pun berbeda.

Hasil penelitian yang didapatkan oleh peneliti dinilai cukup sesuai dengan hasil penelitian sebelumnya yang dilakukan oleh Armayati \& Sumiyati (2015) di Riau. Peneliti sebelumnya mendapati bahwa kecenderungan penggunaan strategi koping pada anak jalanan di Riau adalah emotional focused coping. Menurut Armayati \& Sumiyati (2015), anak jalanan di Riau cenderung mengatasi masalah dengan cara menghindar atau mengalihkan masalah dengan hal-hal yang disenangi, seperti merokok, minum minuman keras, dan obat-obatan.

Hasil penelitian serupa juga didapatkan oleh Zerihun (2015) yang melakukan penelitian berjudul "Problem and Coping Strategy of Street Children, the Case of Nekemte Town, Ethiopia”. Zerihun (2015) mendapati bahwa sebanyak $27,6 \%$ respondennya melakukan penyalahgunaan zat untuk menghindari permasalahan psikologis yang dihadapinya. Hal ini termasuk ke dalam sub variabel distancing yang termasuk ke dalam emotional focused coping strategy.

Dalam penelitian ini terdapat beberapa keterbatasan penelitian, seperti instrumen yang belum valid $100 \%$ karena tidak diuji ulang setelah dimodifikasi. Oleh sebab itu, peneliti merekomendasikan penelitian selanjutnya agar mempersiapkan waktu yang lebih panjang dalam pengambilan data dan juga mengambil sampel atau populasi yang lebih luas. Dengan demikian, penelitian berikutnya tidak mengalami keterbatasan yang serupa.

\section{SIMPULAN}

Rata-rata usia anak didik di SMP Master Kota Depok adalah 14,34 tahun, sebagian besar bekerja sebagai pedagang, mayoritas anak memiliki pengalaman dikucilkan atau diasingkan, dan berpindah-pindah tempat tinggal. Sementara itu, mayoritas anak tidak pernah mengalami kekerasan dan tidak menggunakan NAPZA.

Berdasarkan hasil penelitian, sebagian besar anak jalanan di SMP Master Kota 
Depok juga menerima jenis pola asuh otoritatif. Hasil penelitian ini menunjukkan bahwa sebagian besar anak jalanan di SMP Master Kota Depok mengalami stres tingkat sedang dan menggunakan emotional focused coping sebagai strategi koping yang digunakan saat menghadapi masalah.

Hasil penelitian ini dapat digunakan oleh perawat sebagai landasan menjadi advokat di Sekolah Master Kota Depok. Mengingat banyaknya stresor yang dihadapi oleh anak-anak di SMP Master Kota Depok, menjadikan anak-anak disana membutuhkan fasilitas untuk konseling, serta membutuhkan berbagai informasi mengenai stres dan cara penanganannya dengan menggunakan strategi koping yang tepat. Perawat dapat bekerja sama dengan pihak sekolah, khususnya Sekolah Master Kota Depok untuk memfasilitasi kegiatan yang bertujuan untuk memberikan informasi mengenai cara mengatasi stres pada anak jalanan yang menjadi peserta didik di SMP Master Kota Depok dengan strategi koping yang tepat.

\section{DAFTAR PUSTAKA}

Armayati, L. \& Sumiyati. (2015). Studi deskriptif strategi coping anak jalanan di Riau. An - Nafs., 9(05): 26-33.

Badan Pusat Statistik Provinsi Jawa Barat. (2015). Jawa Barat dalam angka: Jawa Barat in figure 2015. Bandung: BPS Provinsi Jawa Barat.

Boenisch, E. \& Haney, C. M. (2005). The stres owner's manual (meaning, balance and health in your life). Jakarta: GrasindoCohen, S., Kamarck, T., Mermelstein, R. (1983). A Global measure of perceived stress. Journal of Health and Social Behaviour, 24: 385396.

Hamid, A. (2010). Perlindungan sosial anak dan masalahnya. Retrieved from http:// www.kemsos.go.id/modules.php?name
=Contentdanpa=showpagedanpid=16.

Lazarus, R. S. \& Folkman, S. (1984). Stress, apraisal, and coping. New York: Spinger Publishing Company.

Lazarus, R. S. \& Folkman, S. (1988). Ways of Coping Questionnaire. USA: Consulting Psychologist Press, Inc

Lestari, S. (2012). Psikologi keluarga: Penanaman nilai dan penanganan konflik dalam keluarga. Jakarta: Kencana Prenada Media Group.

Noprianto. (2015). Pola asuh orang tua anak jalanan di Kota Makasar. Jurnal Sosialisasi Pendidikan Sosiologi-FIS UNM, 107-111.

Nugroho, P.A., Herani, I., \& Akhrani, L. A. (2012). Motivasi berhenti menggunakan narkoba pada anak jalanan pengguna narkoba berdasarkan teori Abraham Maslow (skripsi). Universitas Brawijaya, Malang, Indonesia.

Persada, R. M. K. B. (2012). Kekerasan personal terhadap anak jalanan sebagai individu dalam ruang publik (Studi kasus terhadap tiga anak jalanan laki-laki binaan Rumah Singgah Dilts Foundation (Skripsi). Universitas Indonesia, Jakarta, Indonesia.

Potter, P. A. \& Perry, A. G. (2009). Fundamental of nursing: Concepts, process, and practice $\left(7^{\text {th }}\right.$ edition.). Singapore: Elsevier.

Purwoko, T. (2013). Analisis faktor-faktor penyebab keberadaan anak jalanan di Kota Balikpapan. E-Journal Sosiologi 2013, 1(4): 13-25.

Segal, J., Smith, M., Segal, R., \& Robinson, L. (2016). Stres symptoms, signs, and causes. Retrieved from http://www. helpguid e.org/articles/stres/st ressymptoms-causes-and-effects.htm.

Titaheluw, K., Kanine, E., \& Kallo, V. (2014). Perbedaan respon stres-adaptasi pada remaja jalanan Komunitas Dinding Pasar 
Bersehati dan remaja Panti Asuhan Bakti Mulia Manado. Jurnal Keperawatan, 2(2): 54-61.

UNICEF. (2012). A study on street children in Zimbabwe. Retrieved from https://www. unicef.org/evaldatabase/files/ZIM_01805.pdf.

WHO. (2010). Module 1. Retrieved from http:// apps.who.i nt/iris/bitstr eam/10665/66 756/2/WHO_MSD_MDP_00.14 Module1.pdf.

Zerihun, A. (2015). Problem and coping strategy of street children, the case of Nekemte Town, Ethiophia (thesis). Addis Ababa University, Ethiopia. 